weeks' gestation had raised death rates from noncardiovascular causes, reflected in higher rates from all causes combined. This was unexpected and requires confirmation by continued follow up and other studies now in progress. The babies born after term had larger head size, which was also associated with higher rates of disease other than cardiovascular disease.

In conclusion, this study shows for the first time that reduced fetal growth is followed by higher death rates from cardiovascular disease in adult life. Bodily proportions at birth suggest that the growth reduction began early in gestation. We suggest that this is further evidence that cardiovascular disease originates through programming in fetal life and infancy. Maternal nutrition may be an important influence on programming.

We are grateful to Mr D R Millar, consultant obstetrician; Mrs Bullas and the staff of the medical records department at the Jessop Hospital for Women who preserved the records and allowed us to use them; and to the staff at NHS central registry and OPCS who traced the men. The study was supported by a grant from the Wellcome Trust.

1 Barker DJP, Winter PD, Osmond C, Margetts B, Simmonds SJ. Weight in infancy and death from ischaemic heart disease. Lancet 1989;ii:577-80.

2 Barker DJP, Meade TW, Fall CHD, Lee A, Osmond C, Phipps K. The relation of fetal and infant growth to plasma fibrinogen and factor VII in adult life. BMF 1992;304:148-52.

3 Hales CN, Barker DJP, Clark PMS, Cox LJ, Fall C, Osmond C, et al. Fetal and infant growth and impaired glucose tolerance at age 64. BMY 1991;303:1019-22.

4 Barker DJP, ed. Fetal and infant origins of adult disease. London: British Medical Journal, 1992.

5 Lucas A. Programming by early nutrition in man. In: Bock GR, Whelan J, eds. The childhood environment and adult disease. Ciba Foundation Symposium 156. Chichester: John Wiley, 1991:38-50.
6 Dubos R, Savage D, Schaedler R. Biological Freudianism: lasting effects of early environmental influences. Pediatrics 1966;38:789-800.

7 Winick $M$, Noble $A$. Cellular response in rats during malnutrition at various ages. F Nutr 1966;89:300-6

8 Blackwell NM, Blackwell RQ, Yu TTS, Weng YS, Chow BF. Further studies on growth and feed utilization in progeny of underfed mother rats. I Nutr 1968;97:79-84.

9 Hahn P. Effect of litter size on plasma cholesterol and insulin and some liver and adipose tissue enzymes in adult rodents. I Nutr 1984;114:1231.

10 Law CM, Barker DJP, Bull AR, Osmond C. Maternal and fetal influences on blood pressure. Arch Dis Child 1991;66:1291-5.

11 Barker DJP, Godfrey KM, Osmond C, Bull A. The relation of fetal length, ponderal index, and head circumference to blood pressure and the risk of hypertension in adult life. Paediatr Perinat Epidemiol 1992;6:35-44.

12 Barker DJP, Bull AR, Osmond C, Simmonds SJ. Fetal and placental size and risk of hypertension in adult life. $B M \mathcal{F}$ 1990;301:259-62.

13 Berry G. The analysis of mortality by the subject-years method. Biometric 1983;39:173-84.

14 Phipps K, Barker DJP, Hales CN, Fall CHD, Osmond C, Clark PMS. Fetal growth and impaired glucose tolerance in men and women. Diabetologia 1993. (In press.)

15 Gardner MJ, Winter PD, Barker DJP. Atlas of mortality from selected diseases in England and Wales, 1968-78. Chichester: Wiley, 1984.

16 Barker DJP, Hales CN, Fall CHD, Osmond C, Phipps K, Clark PMS. Noninsulin dependent diabetes, hypertension and hyperlipidaemia (syndrome $\mathrm{X}$ ): relation to reduced fetal growth. Diabetologia 1993;36:62-7.

17 Fall CHD, Barker DJP, Osmond C, Winter PD, Clark PMS, Hales CN. Relation of infant feeding to adult serum cholesterol concentration and death Relation of infant feeding to adult serum cholesterol
from ischaemic heart disease. $B M{ }^{\mathcal{O}} 1992 ; 304: 801-5$.

18 Beischer MA, Sivasamboo R, Vohra S, Silpisom Rosal S, Reid S. Placental hypertrophy in severe pregnancy anaemia. $f$ Obstet Gynaecol, Br Commw 1970;77:398-409.

19 Godfrey KM, Redman CWG, Barker DJP, Osmond C. The effect of maternal anaemia and iron deficiency on the ratio of fetal weight to placental weight. Br F Obstet Gynaecol 1991;98:886-91.

20 Farchney GJ, White GA. Effects of maternal nutritional status on fetal and placental growth and on fetal urea synthesis. Austr f Biol Sci 1987;40: 365-77.

21 McCrabb GJ, Egan AR, Hosking BJ. Matemal undernutrition during midpregnancy in sheep. Placental size and its relationship to calcium transfer during late pregancy. Br Nutr 1991:65:157-68.

22 Butler N, Alberman ED. Second report of the 1958 British perinatal morality survey. Edinburgh and London: Livingstone, 1969.

23 Robinson SM, Wheeler T, Hayes MC, Barker DJP, Osmond C. Fetal heart rate and intrauterine growth. BrF Obstet Gynaecol 1991;98:1223-7.

(Accepted 1 December 1992)

\title{
Sexually transmitted diseases and HIV-1 infection among homosexual men in England and Wales
}

\author{
B G Evans, M A Catchpole, J Heptonstall, J Y Mortimer, C A McCarrigle, A G Nicoll, P Waight, \\ O N Gill, A V Swan
}

Public Health Laboratory

Service AIDS Centre,

Communicable Disease

Surveillance Centre,

London NW9 5EO

B G Evans, consultant

epidemiologist

M A Catchpole, consultant

epidemiologist

JY Mortimer, principal

scientist

C A McGarrigle, senior

scientist

A G Nicoll, consultant

epidemiologist

O N Gill, consultant

epidemiologist

Public Health Laboratory

Service, Communicable

Disease Surveillance

Centre (Immunisation

Division)

J Heptonstall, consultant

microbiologist

P Waight, principal scientist

Public Health Laboratory Service, Statistics Unit

A V Swan, head

Correspondence to:

Dr Evans.

BMF 1993;306:426-8

\section{Abstract}

Objective-To examine surveillance data for evidence of changing sexual behaviour and continuing transmission of HIV-1 among men who have sex with men.

Design-Analytic study of surveillance data on sexually transmitted diseases.

Setting-England and Wales.

Main outcome measures-Number of cases of rectal gonorrhoea and newly diagnosed HIV infection in homosexual men.

Results-New cases of gonorrhoea among men attending genitourinary medicine clinics increased by $7 \cdot 7 \%$ in 1989 and by $4 \cdot 2 \%$ in 1990 . Reports of rectal isolates of Neisseria gonorrhoeae also rose and the male to female ratio for patients with rectal gonorrhoea changed from 0.3:1 during 1988-9 to 2.6:1 in 1990-1. Although the overall number of cases of acute hepatitis $B$ fell during 1988-91, 81 and 82 homosexual men were infected in 1990 and 1991 respectively compared with 50 and 42 in 1988 and 1989. 1526 men had HIV-1 infection diagnosed in 1991, the largest number since 1987. Twenty eight of the $97(29 \%)$ men who seroconverted between January 1989 and December 1991 were aged less than 25 . The proportion of men aged 15-19 who were found to be infected with HIV-1 at their first test increased from an average of $2 \cdot 4 \%$ up to 1990 to $4.7 \%$ in the first nine months of 1991 . The prevalence of HIV infection in men under 25 attending genitourinary medicine clinics in London was $17 \%$ compared with $7 \cdot 8 \%$ outside London.

Conclusion-Unsafe sexual behaviour and HIV transmissions have increased among homosexual men after a period of decline. Recent HIV transmissions may disproportionately affect younger men.

\section{Introduction}

A decline in the incidence of sexually transmitted diseases in men who have sex with men was well documented in the mid-1980s in various developed countries, including the Netherlands, ${ }^{1}$ the United States, ${ }^{2}$ and Britain. ${ }^{3}$ Those undertaking health promotion saw this as evidence that sexual behaviour could be changed and that educational messages about safer sex had been heeded by homosexual men. In Britain, however, homosexual men infected with HIV-1 still contracted gonorrhoea, ${ }^{4}$ which implied continued participation in unprotected sexual intercourse. In 1989 increases in the incidence of sexually transmitted disease in homosexual men in the United States suggested that high risk sexual behaviour between men was increasing after a period of decline. Increases in sexually transmitted diseases in homosexual men were also reported in Amsterdam ${ }^{6}$ and Australia. $^{7}$

In 1990 increases in rectal gonorrhoea in men were noted in several genitourinary medicine clinics in London and elsewhere in Britain. ${ }^{8-13}$ Repeat testing 
of initially seronegative homosexual men showed continuing transmission of HIV-1 infection ${ }^{14}$ and, in London, the incidence of infection increased in 1990-1 compared with earlier years. ${ }^{15}$ Behavioural data from a cohort study supported the view that an increase in high risk sexual behaviour between men occurred in $1989-90 . .^{16}$

\section{Methods}

We examined surveillance data for England and Wales on sexually transmitted diseases. Trends in infections likely to have been transmitted by unprotected sexual intercourse between men were analysed for indications of changes in sexual behaviour.

We reviewed the quarterly $\mathrm{KC} 60$ returns from all genitourinary medicine clinics in England and Wales to determine the number of attenders for each diagnosis, sex, and (for some diagnoses) sexual orientation and age group. Laboratory reports of rectal isolates of Neisseria gonorrhoeae, cases of acute hepatitis B virus infection, and newly diagnosed HIV-1 infection were analysed. Most of the reports of $N$ gonorrhoeae infection included the sex of the patient but not sexual orientation. For a small proportion of patients infected with HIV-1 the year and month of a previous negative HIV-1 test result had been established and we examined the characteristics of these seroconverters. As part of a study of HIV testing 18 laboratories provided aggregate data, by exposure category, on all persons tested. We used these data to calculate the annual age specific prevalence of HIV-1 infection at initial HIV-1 testing among homosexual men. ${ }^{17}$ The unlinked anonymous serosurvey of people attending genitourinary medicine clinics provided further data on the age specific prevalence of HIV infection and acute sexually transmitted disease among homosexual men. Patient diagnosis (KC60 code) is collected in this survey ${ }^{18}$ and grouped into broad categories including acute sexually transmitted diseases (such as gonorrhoea or a first attack of genital herpes). We analysed data, where appropriate, by standard $\chi^{2}$ tests and linear modelling on a log scale assuming the observed frequencies to be distributed as Poisson variables.

\section{Results}

From 1981 to 1988 the number of attendances at a genitourinary medicine clinic for uncomplicated postpubertal gonorrhoea fell consistently (fig 1 (top)). Attendances then began to increase with a $7 \cdot 7 \%$ rise for men in 1989 and a further rise of $4.2 \%$ in 1990 $\left(x^{2}=9495, \mathrm{df}=8 ; \mathrm{p}=0\right)$. Rises in numbers of people with gonorrhoea were observed within and outside the Thames regions in 1989 (J Hilton, personal communication). Although the number of cases of infectious syphilis seen in genitourinary medicine clinics has fallen since 1981, the rate of fall slowed in 1988 (fig 1 (bottom)). A Poisson regression test for non-linearity in the separate trends gave $\chi^{2}$ values of 408 with 16 degrees of freedom $(p<0.001)$.

The annual total of laboratory reports of isolation of $N$ gonorrhoeae in rectal specimens in men fell consistently between 1982 and 1989, with the exception of 1985 . In

TABLE I-Laboratory reports of acute hepatitis $B$ infection in men (aged 15 years or over) by year of diagnosis, England and Wales

\begin{tabular}{lcccccccccc}
\hline & 1982 & 1983 & 1984 & 1985 & 1986 & 1987 & 1988 & 1989 & 1990 & $1991^{\star}$ \\
\hline Homosexual or bisexual & 104 & 115 & 141 & 126 & 110 & 50 & 52 & 42 & 81 & 82 \\
No risk information & 346 & 322 & 457 & 468 & 352 & 231 & 203 & 226 & 180 & 140 \\
Others & 414 & 450 & 687 & 612 & 383 & 231 & 185 & 141 & 145 & 121 \\
\hline Total & 864 & 887 & 1285 & 1206 & 845 & 512 & 440 & 409 & 406 & 343 \\
\hline
\end{tabular}

TABLE II-Newly diagnosed and reported HIV-1 infection in men who have sex with men, England and Wales

<1985 $1986 \quad 1987 \quad 1988 \quad 1989 \quad 1990 \quad 1991$

\begin{tabular}{lrrrrrrr}
\hline Annual total & 1396 & 1600 & 1546 & 1062 & 1116 & 1428 & 1526 \\
No for whom age known & 1273 & 1488 & 1465 & 1028 & 1075 & 1415 & 1521 \\
Median age (years) & 33 & 32 & 33 & 33 & 33 & 32 & 31 \\
No aged 20-24 & 207 & 242 & 238 & 121 & 135 & 181 & 177 \\
No aged <19 & 20 & 28 & 26 & 14 & 20 & 26 & 27 \\
\hline
\end{tabular}

TABLE II-Year of seroconversion in 307 homosexual men who had had negative test results, England and Wales

\begin{tabular}{lccccccc}
\hline & \multicolumn{7}{c}{ Year of first positive result } \\
\cline { 2 - 8 } $\begin{array}{l}\text { Year of last } \\
\text { negative result }\end{array}$ & 1985 & 1986 & 1987 & 1988 & 1989 & 1990 & 1991 \\
\hline 1985 & 16 & 21 & 10 & 3 & 4 & 3 & 2 \\
1986 & & 13 & 18 & 1 & 5 & 3 & 7 \\
1987 & & & 13 & 6 & 9 & 16 & 7 \\
1988 & & & & 7 & 19 & 13 & 14 \\
1989 & & & & & 6 & 25 & 11 \\
1990 & & & & & & 14 & 29 \\
1991 & & & & & & & 12 \\
\end{tabular}

1990 and 1991, however, reports of isolates from men increased fivefold (fig 2). From 1986 to 1989 most rectal isolates were from women, but in 1990 and 1991 reports from men outnumbered those from women by more than 2.5 to 1 . The trends over time were significantly different in the two sexes $\left(\chi^{2}=275, \mathrm{df}=9\right.$; $p<0.0001)$ and significantly non-linear $\left(\chi^{2}=514\right.$, $\mathrm{df}=16 ; \mathrm{p}<0.0001$ ).

The number of cases of acute hepatitis $B$ diagnosed each year in men aged 15 years or over increased during the early 1980 s, and reached a peak of 1285 in 1984. Annual numbers fell rapidly from 1985 to 1987 and more gradually thereafter (table I). The trend was significantly non-linear $\left(\chi^{2}=506 \cdot 3, \mathrm{df}=8\right.$; $\mathrm{p}<0.0001)$. Only 343 cases were diagnosed and reported in 1991 (provisional data) in men aged 15 years or over, fewer than in any of the preceding 10 years. More than 80 cases in homosexual men were reported in both 1990 and 1991, double the 42 cases reported in 1989 and higher than the number reported in any year since 1986 . This trend was also significantly non-linear $\left(\chi^{2}=74, \mathrm{df}=8 ; \mathrm{p}<0.0001\right)$.

\section{HIV INFECTION}

For 1988 the number of reports of newly diagnosed HIV-1 infection in men who had had sex with men (1062) was the lowest in any year since the widespread introduction of testing. After 1988 it increased each year to 1526 in 1991 (table II). The median age of homosexual men with recently diagnosed HIV-1 infection did not increase, and both the number and the proportion of HIV-1 infections diagnosed in younger homosexual men remained similar over time (table II). In 1990 and 1991, $358(12 \%)$ cases were in men aged $20-24$ and $53(2 \%)$ in men aged 19 years or under. Among the two thirds for whom information on symptoms was supplied at the time of diagnosis of HIV-1 infection, the proportion asymptomatic remained relatively constant: $53 \%$ in $1986-7,46 \%$ in $1988-9$, and $52 \%$ in $1990-1$.

A previous negative test result was recorded for 307 of the homosexual men infected with HIV (table III). Rolling totals were calculated for successive three year periods: in 1985-7 there were 91 homosexual men who had a negative test followed by a positive one; in 1986-8 there were 58 such men; in 1987-9 there were 60 ; in 1988-90 there were 84; and in 1989-91 there were 97 (table III). Of the 97 men known to have seroconverted during 1989-91 28 (29\%) were aged under 25. Among asymptomatic homosexual men newly diagnosed as infected with HIV during 1989-91 the proportion under 25 was $17 \%$ (271 of 1570 ).

During 1987 to 1991,958 homosexual men aged 19 
years or under had, for clinical purposes, had a first HIV test at one of the 18 laboratories participating in the study of HIV testing. Between 149 and 194 were tested annually from 1987 to 1990 and the prevalence of HIV-1 infection ranged from $2 \cdot 1 \%$ to $2 \cdot 7 \%$. However, in $1991,12(4.7 \%)$ of the 257 men tested were infected. This is significantly more than should occcur by chance if the true risk were equal to the largest previously observed proportion $(p=0 \cdot 04)$.

Data from the unlinked anonymous genitourinary medicine clinic serosurvey showed that in 1990, 343 of $1391(25 \%)$ samples from non-drug injecting homosexual men in two London clinics were infected with HIV-1 compared with only 20 of $356(5.6 \%)$ from men in four clinics outside London $\left(\chi^{2}=63.5, \mathrm{df}=1\right.$; $\mathrm{p}<0.0001)$. The prevalence of HIV-1 infection recorded in those aged less than 25 years was $17 \%(52 / 305)$ among those tested in London and $7 \cdot 8 \%(8 / 103)$ among those tested outside London $\left(\chi^{2}=5 \cdot 5, \mathrm{df}=1 ; \mathrm{p}=0.02\right)$. Of the 363 homosexual men who tested HIV-1 positive, $80(22 \%)$ had an acute sexually transmitted disease diagnosed at the time blood was collected for investigation of syphilis.

\section{Discussion}

The extent to which isolation of $N$ gonorrhoeae is indicative of risk of HIV-1 infection is debatable, ${ }^{12}$ but it is reasonable to regard rectal gonorrhoea as a marker for high risk homosexual behaviour. ${ }^{11}$ Thus the increase in gonorrhoea in men attending genitourinary medicine clinics in 1989 and 1990 and the increase in rectal isolates of $N$ gonorrhoeae in men suggest that the behaviour associated with risk of HIV-1 transmission among homosexual men has also increased. The rise in the number of rectal isolates of $N$ gonorrhoeae in men reported for England and Wales in 1990 is not attributable to an increase in the number of reporting laboratories, and the marked shift in the male to female ratio of cases from which these isolates were obtained is unlikely to be caused by changes in the catchment population.

Although further research would be necessary to establish the extent to which sexual practices which limit the risk of HIV transmission overlap with those which would prevent transmission of hepatitis B virus, the rise in hepatitis B infection reported in homosexual men is also suggestive of increased unsafe sex in this group. An effective vaccine is available against hepatitis $B$ and thus increasing incidence of acute hepatitis $B$ infection reflects the failure of health care providers to deliver hepatitis $B$ vaccine to those at risk. A postal survey of genitourinary medicine clinics in 1988 showed that a third offered hepatitis B vaccine to clinic attenders, ${ }^{19}$ and a recent audit report from a London genitourinary medicine clinic estimated that vaccine was delivered successfully to only a quarter of susceptible new homosexual patients. ${ }^{20}$ At present, it seems, acute hepatitis B in homosexual men is a more effective marker of unsafe sex than it should be.

New reports of HIV infection in men who have sex with men disproportionately could relate to people who were infected before the implementation of health education programmes but delayed having a test. If this was the case new reports would be expected to include fewer recent infections and the average age of people with newly diagnosed HIV infection and the proportion symptomatic at the time of the HIV-1 test would rise. As neither has happened it is probable that the incidence of HIV-1 infection among homosexual men has not fallen. The $5.6 \%$ annual infection rate among initially uninfected homosexual men in London who had repeat HIV-1 tests during 1990-1 15 and the presence of HIV-1 infection in one in 20 homosexual men aged 19 years or under who were first tested during 1990-1 are further indications that transmissions continue. Transmission of infection is occurring both among the young, who may not have been fully exposed to the health education of the mid-1980s, and in older age groups, who may have changed to unsafe sex practices after previously heeding health advice. Two thirds of recognised seroconversions were in men aged 25 years or over, and the increase in sexually transmitted diseases was not confined to young men.

As the prevalence of HIV-1 infection among homosexual men has risen so the risk of exposure to HIV-1 with each unsafe sexual encounter will have increased. Moreover, the data from the unlinked anonymous survey shows that some men who knew they were infected with HIV-1 still acquired acute sexually transmitted diseases..$^{21}$ If they acquired these infections from HIV negative partners, those partners will have been at risk of HIV infection. The continuation of high risk behaviour in this group, who would have been counselled about safe sex when tested for HIV-1 infection, is of particular concern, as are seroconversions in those known to have had a negative test result. In the first case counselling has failed to protect others and in the second it has failed to protect the person counselled.

The data examined in this study give a consistent picture of behaviour changes among homosexual men which have led to a continuance of HIV transmission in this group in England and Wales. Because of the high background prevalence of HIV-1 infection risks to homosexual men practising unsafe sex are greatest in London. Health promotion for all men who have sex with men is important, but safe sex information aimed at young homosexual men and homosexual men in London needs special emphasis.

1 van de Laar MJW, Pickering J, van der Hoek JAR, van Griensven GJP, Coutinho RA, van de Water HPA. Declining gonorrhoea rates in the Netherlands, 1976-88; consequences for the AIDS epidemic. Genitourin Med 1990;66:148-55.

2 Winkelstein W, Samuel M, Padian NS, Wiley JA, Lang W, Anderson RE, et al. The San Francisco men's health study. III. Reduction in human immunodeficiency virus transmission among homosexual-bisexual men, 1982-86. Am f Public Health 1987;76:685-9.

3 Johnson AM, Gill ON. Evidence for recent changes in sexual behaviour in homosexual men in England and Wales. Philos Trans $R$ Soc Lond [Biol] 1989;325:153-61.

4 Lawrence AG, Singaratnam AE. Changes in sexual behaviour and incidence of gonorrhoea. Lancet 1987; i:982-3.

5 Handsfield HH, Krekeler B, Nicola RM. Trends in gonorrhea in homosexually active men, King County Washington 1989. MMWR 1989;38:762-4.

6 Van den Hoek JAR, van Griensven GJP, Coutinho RA. Increase in unsafe homosexual behaviour. Lancet 1990;336:179-80.

7 Forsyth JRL, Sherrard J, Traynor P. Resurgent gonorrhoea in homosexual men. Lancet 1990;336:878.

8 Riley VC. Resurgent gonorrhoea in homosexual men. Lancet 1991;337:183.

9 Waugh MA. Resurgent gonorrhoea in homosexual men. Lancet 1991;337:375.

10 Ross JDC, McMillan A, Young H. Increasing incidence of gonorrhoea and syphilis in homosexual men in Edinburgh. Communicable Disease and Environmental Health in Scotland 1991;25(91/04):3-4.

11 Young H, Moyes A, McKenna JG, McMillan A. Rectal gonorrhoea and unsafe sex. Lancet 1991;337:853.

12 Tomlinson DR, French PD, Harris JRW, Mercey DE. Does rectal gonorrhoea reflect unsafe sex? Lancet 1991;337:501-2.

13 Singaratnam AE, Boag F, Barton SE, Hawkins DA, Lawrence AG. Preventing the spread of HIV infection. BMF 1991;302:469.

14 Waight PA, Miller $\mathrm{E}$. Incidence of HIV infection among homosexual men. BMF 1991;303:311.

15 Waight PA, Rush AM, Miller E. Surveillance of HIV infection by voluntary testing in England. Communicable Disease Report 1992;2:R85-90.

16 Hunt AJ, Davies PM, Weatherburn P, Coxon AP, McManus TJ. Changes in sexual behaviour in a large cohort of homosexual men in England and Wales, 1988-9. BMF 1991;302:505-6.

17 Public Health Laboratory Service Working Group. Prevalence of HIV antibody in high and low risk groups in England. $B M{ }^{\prime}$ 1989;298:422-3.

18 Public Health Laboratory Service and Collaborators. Unlinked anonymous monitoring of HIV prevalence in England and Wales 1990-1992. Communicable Disease Report 1993;3:R1-11.

19 Loke RHT, Murray-Lyon IM, Balachandran T, Evans BA. Screening for hepatitis $B$ and vaccination of homosexual men. BMF 1989;298:234.

20 Bhatti N, Gilson RJ, Beecham M, Williams P, Mathews MP, Tedder RS, et al. Failure to deliver hepatitis $B$ vaccine: confessions from a genitourinary et al. Failure to deliver hepatitis $B$ vaccin
medicine clinic. $B M Y$ 1991;303:97-101.

21 Nicoll A, Catchpole M, Gill ON, Mahoney A, Mercey D, Mortimer P, et al. HIV sentinel surveillance amongst STD clinic attenders: England and HIV sentinel surveillance amongst STD clinic attenders: England and
Wales. [Abstract POC 4008.] In: Proceedings of international conference on AIDS/III STD world congress, Amsterdam fuly 1992. Netherlands: Congrex Holland B.V, 1992.

(Accepted 27 November 1992) 